\title{
11. Zur Kenntnis der Polyphenolasen.
}

\author{
Von Eijiro YaKUSHIJI. \\ Iwata Institut für Pflanzenbiochemie. \\ (Comm. by K. ShibatA, M.I.A., Feb. 12, 1940.)
}

In neuerer Zeit ist ein wesentlicher Fortschritt in der Reindarstellung der Polyphenolasen erzielt. Aber ihre spezifischen Eigenschaften und Wirkungsweisen sind öfters nicht genügend scharf charakterisiert, sodass eine richtige Klassifizierung sowie Benennung der betreffenden Enzyme heute noch nur schwer durchführbar ist. Um zur Aufklärung dieser Sache gewissermassen beizutragen, habe ich in vorliegender Arbeit meine bisherigen Versuchsergebnisse über einige Polyphenolasen kurz und vergleichend dargestellt.

\section{Laccase.}

a) Laccase des Lackbaums.

D. Keilin und T. Mann" haben neuerdings aus Rohlack von Rhus succedanea die Laccase als ein blauer Kupfer-Protein-KohlehydratKomplex isoliert. Dieses Präparat enthielt $0.15 \% \mathrm{Cu}$ und $6.45 \% \mathrm{~N}$. Es oxydiert $p$-Phenylendiamin am kräftigsten $\left(\mathrm{QO}_{2}=40000\right)$ und wird durch $\mathrm{KCN}, \mathrm{H}_{2} \mathrm{~S}$ und Na-Diäthyldithiocarbaminat gehemmt, aber nicht durch CO. Auch ich habe aus dem Lacksaft von Rhus succedanea und von Rhus vernicifera dasselbe blaue Ferment isoliert. Dieses Ferment oxydiert $p$-Phenylendiamin und zahlreiche $o$ - und $p$-Polyphenole wie Pyrogallol, Brenzcatechin, Hydrochinon u.s.w., ${ }^{2)}$ aber oxydiert nicht Resorcin und $p$-Kresol. Ascorbinsäure wird, wie schon von Keilin und Mann $^{1)}$ beobachtet wurde, ohne Zusatz von Chinonbildnern oxydiert. Es ist aber fraglich, ob und inwieweit diese Ascorbinasewirkung der reinen Laccase zugeschrieben werden kann, da, wie ich vor kurzem gezeigt habe, ${ }^{3)}$ sich eine hämatinhaltige Peroxydase, die zwar eine stärkere Ascorbinasewirkung aufweist, im Gang der Reindarstellung durch Kaolinadsorption von der Laccasefraktion abtrennen liess.

b) Pilzlaccase.

Ich habe schon früher das polyphenoloxydierende Ferment) aus Lactarius piperatus in Bezug auf seine spezifische Wirkungsweise näher untersucht und gefunden, dass es mit der Laccase aus Lackbaum sehr nahe verwandt ist. Ich habe nun durch die verbesserte Reinigungsmethode aus dem Extrakt dieses Pilzes das Ferment als ein blaugefärbtes kupferhaltiges Protein isoliert. Die früher beschriebene hämatinhaltige Beimengung wurde vollständig entfernt.

1) D. Keilin u. T. Mann: Nature, 143 (1939), 23.

2) Vgl. K. Suminokura: Bull. Chem. Soc. Japan, 11 (1936), 299.

3) E. Yakushiji : Acta Phytochim., 11 (1939), 190.

4) E. Yakushiji : Acta Phytochim., 10 (1937), 63. 
Darstellung: Frisch gesammeltes Pilzmaterial wurde sofort in Aceton eingetragen, zerkleinert und zerrieben. Es wurde gründlich mit Aceton, dann mit Äther gewaschen, abgesaugt und gleich mit der Lösung von sekundärem Phosphat übernacht extrahiert. Dieser Extrakt wurde mit festem Ammoniumsulfat zur Sättigung versetzt, die entstandene Fällung abgesaugt und in Wasser gelöst. Aus dieser Lösung wurde die Laccase mit Ammoniumsulfat vom 0.5-0.67 Sättigungsgrad gefällt. Die gelbe Beimengung wurde durch Adsorption an Kaolin oder Tierkohle oder durch Chloroformbehandlung entfernt. Die blaue Lösung wurde dialysiert, mit Aceton gefällt und im Exsikkator getrocknet. Ausbeute $0.15 \mathrm{~g}$ aus $9 \mathrm{~kg}$ Pilzen. Analyse dieses Präparats ergab: $0.34 \% \mathrm{Cu}, 13.83 \% \mathrm{~N}$ und $8.2 \%$ Wasser.

Spektroskopische Eigenschaften: Eine konzentrierte Lösung der Pilzlaccase zeigt unter Mikrospektroskop bei $\underbrace{560600}_{580} \mathrm{~m} \mu$ ein ver-

waschenes Band wie bei Hämocyanin. Im Ultraviolett zeigt sie eine Bande bei $332 \mathrm{~m} \mu$ und die Proteinabsorption bei etwa $280 \mathrm{~m} \mu$.

Die Wirksamkeit dieses Fermentpräparats wurde manometrisch mit Warburgschem Apparat bestimmt. $\mathrm{Qo}_{2}$ gemessen bei $25^{\circ} \mathrm{C}$ für verschiedene Substrate ist folgende: Pyrogallol 150000, $p$-Phenylendiamin 80000 , Hydrochinon 60000, Brenzcatechin 50000, Phloroglucin 30000, Eugenol und Guajakol 60000, p-Kresol 6000, Resorcin 3600 und Ascorbinsäure 30000. Die Sauerstoffaufnahme bei $p$-Kresol verläuft ohne Färbung, sondern mit weisser Trübung der Reaktionslösung. Tyrosin, $o$ - und $m$-Kresol wurden mit diesem gereinigten Präparat gar nicht oxydiert.

\section{Tyrosinase (Monophenolase, Catecholoxydase).}

Tyrosinase oxydiert neben o-Polyphenole auch Monophenole, z. B. Tyrosin, Carbolsäure, $p$-Kresol, $m$-Kresol u. a. ${ }^{1}$ In der Literatur ist aber dieses Ferment öfters bloss als Polyphenolase oder als Catecholoxydase genannt, da es Brenzcatechin kräftig oxydiert. Diese vieldeutige Bezeichnung soll besser mit dem früher gebrauchten Name "Tyrosinase “ ersetzt werden, obwohl die Wirksamkeit gegenüber Tyrosin nicht immer gross ist. Das von F. Kubowitz ${ }^{2)}$ aus Kartoffel sowie das von D. Keilin und T. Mann ${ }^{3)}$ aus Psalliota campestris rein isolierte Ferment gehört hierher. Auch die Tyrosinase enthält $\mathrm{Kupfer}^{4}$ in der aktiven Gruppe, aber ist nicht blau gefärbt wie die Laccase. Sie lässt sich auch durch seine ausgeprägte CO-Empfindlichkeit von der Laccase unterscheiden.

Ich habe gefunden, dass in einem Tyrosinasepräparat aus Lactarius. vellereus, das von Herrn Dr. T. Mori mir freundlichst zur Verfügung

1) H.S. Raper: Ergebnisse d. Enzymforsch., 1 (1982), 270.

F. Kubowitz: Biochem. Ztschr., 299 (1938), 53.

2) F. Kubowitz: Biochem. Ztschr., 292 (1937), 221 ; 296 (1938), 443 ; 299 (1938), 32.

3) D. Keilin u. T. Mann: Proc. Roy. Soc., (B) 125 (1938), 187.

4) F. Kubowitz: loc. cit.; D. Keilin u. T. Mann : loc. cit.

Vgl. auch H. R. Dalton u. J. M. Nelson: J. Am. Chem. Soc. 60 (1938), 3085; 61 (1939), 2946. 
gestellt wurde, ein kochstabiler Aktivator beigemengt vorkommt, welcher die Oxydation des $p$-Kresols durch dieses Enzym stark befördert. Dieser Aktivator ist bei der Tyrosinase aus Kartoffel und aus Winterknospen von Sagittaria trifolia gleichfalls wirksam. Neuerdings haben $H$. R. Dalton und J. M. Nelson ${ }^{1}$ aus Lactarius piperatus die Tyrosinase krystallinisch erhalten. Nach diesen Autoren sinkt die Wirksamkeit des Ferments gegenüber $p$-Kresol bei der Krystallisation vielfach ab, was auch deutlich auf die Existenz des Aktivators hinweist.

\section{Orthophenolase.}

Die Wurzelknollen von Ipomoea Batatas enthalten ein o-Polyphenole oxydierendes Ferment, das nicht imstande ist, $p$-Kresol und Tyrosin anzugreifen.) Es bleibt gegen $p$-Kresol unwirksam auch in Gegenwart vom Aktivator aus Lactarius vellereus. Graubard ${ }^{3 \prime}$ hat dieses Ferment mit Recht für von der Tyrosinase verschieden gehalten und „, Catecholoxydase “ bezeichnet. Da aber die Kartoffel-Tyrosináse in der Literatur schon öfters als Catecholoxydase genannt worden ist, soll man besser das Ipomoea-Ferment mit einem neuen Name „Orthophenolase “ kennzeichnen.

Zum Schluss sage ich meinem verehrten Lehrer, Herrn Prof. Dr. K. Shibata, für seine Leitung und Anregung meinen besten Dank.

1) H. R. Dalton u. J. M. Nelson: J. Am. Chem. Soc., 60 (1938), 3085; 61 (1939),

2) M. H. Adams u. J. M. Nelson: J. Am. Chem. Soc., 60 (1938), 2474.

3) M. Graubard: Enzymologia, 5 (1938-39), 333. 